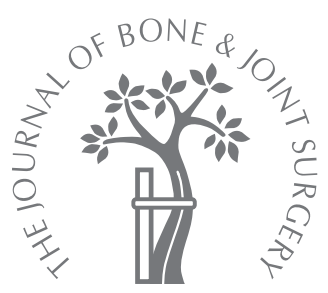

T. Ji,

W. Guo,

R.-L. Yang,

S. Tang,

X. Sun

From Peking

University People's

Hospital, Beijing,

China
T. Ji, MD, Orthopaedic

Surgeon

W. Guo, MD, PhD, Professor

R.-L. Yang, Senior

Orthopaedic Surgeon

S. Tang, MD, Orthopaedic

Surgeon

X. Sun, MD, Orthopaedic

Registrar

Musculoskeletal Tumor Centre Peking University People's

Hospital, 11\# Xizhimen Nan

Road, Xicheng District, Beijing

100044, China.

Correspondence should be sent to Professor W. Guo; e-mail:

bonetumor@163.com

(C)2011 British Editorial Society of Bone and Joint Surgery doi:10.1302/0301-620X.93B8. $26155 \$ 2.00$

$J$ Bone Joint Surg $[\mathrm{Br}]$ 2011;93-B:1104-10.

Received 1 November 2010;

Accepted after revision 7 April

2011

\title{
Clinical outcome and quality of life after surgery for peri-acetabular metastases
}

\begin{abstract}
We set out to determine the impact of surgery on quality of life and function in patients who had undergone surgery for symptomatic peri-acetabular metastases. From a prospective database we retrospectively reviewed 46 consecutive patients who had been treated operatively between June 2003 and June 2009. The mean age of the patients was 56.4 years (20 to 73) and the mean post-operative follow-up was 19.2 months (4 to 70). Functional evaluation and quality-of-life assessments were performed. At the most recent follow-up, 26 patients $(56.5 \%)$ were alive. Their median survival time was $\mathbf{2 5 . 0}$ months. Ten major postoperative complications had occurred in eight patients (17.4\%). The mean post-operative Musculoskeletal Tumor Society score (MSTS 93) was $56.3 \%$ (6.7\% to $90.0 \%$ ). Improvement in the Eastern Cooperative Oncology Group (ECOG) performance status was seen in 32 patients $(69.6 \%)$. On the European Organisation for Research and Treatment of Cancer core quality-of-life questionnaire (OLO-C30) measure of global health status there was a statistically significant improvement from the patients' pre-operative status (42.8 (SD 13.7)) to that found at the latest follow-up (58.0 (SD 12.5)) $(p=0.001)$. The only statistically significant change in the nine symptom domains of the QLO-C30 was a reduction in the mean level of pain (from 59.1 to 29.5 (out of 100)) ( $p<0.001$ ).

Surgery for patients with peri-acetabular metastases reduces pain and improves their quality of life, and has a low rate of surgical complications.
\end{abstract}

Improvements in the treatment of cancer have resulted in prolonged survival and an increase in the number of patients with metastases. ${ }^{1}$ Metastatic bone disease affecting the pelvis and acetabulum is increasingly encountered by oncologists and orthopaedic surgeons. ${ }^{2-4}$ Some metastatic deposits are associated with instability of the acetabulum, which may cause severe pain and functional disability. An effective method of treatment should relieve pain and restore function for as long as possible. ${ }^{5}$

It has been shown that surgery can reduce the morbidity of metastatic bone disease, relieve pain, maintain mobility and independence and improve the patient's quality of life. ${ }^{5-8}$ Surgical reconstruction of periacetabular pelvic lesions is complex, involving long operating times, extensive exposure and considerable blood loss. ${ }^{9-11}$ The effect of this surgery on quality of life (QoL) remains unknown. ${ }^{12}$ Most studies have dealt with surgical procedures and survival; few have addressed the QoL of patients after surgical treatment for peri-acetabular metastases. ${ }^{6} \mathrm{We}$ believe that a multidimensional assessment of QoL is more relevant to the management of these patients, particularly when assessing the risks and benefits of surgery.

The purpose of this study was to determine the impact of surgery on health-related QoL and function in survivors after surgical treatment for peri-acetabular metastases.

\section{Patients and Methods}

From a prospective database we retrospectively reviewed 46 consecutive patients treated operatively for symptomatic metastatic peri-acetabular disease between June 2003 and June 2009. Exclusion criteria included previous surgery for pelvic metastases and an inability to complete a questionnaire. The medical records and radiographs of these patients were reviewed after approval by the Institutional Review Board. Informed consent for participation in the study was obtained from the patients or their families. The local extent of the tumour, type of excision and reconstruction performed were noted. The patients were assessed before surgery and at three and six months after surgery. Findings at the most recent review were recorded for the patients who were still alive. Their survival 


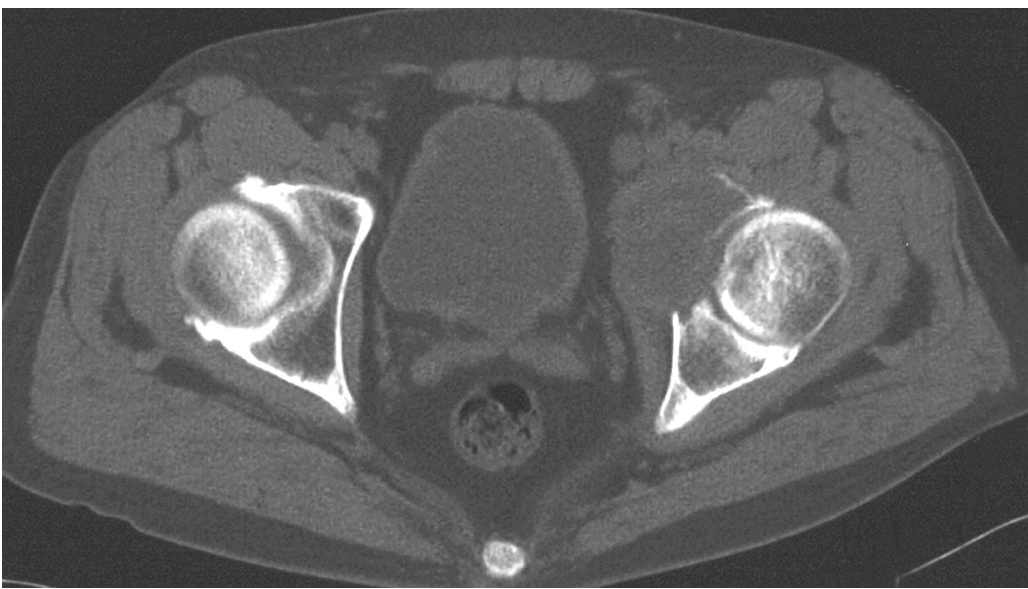

Fig. 1a

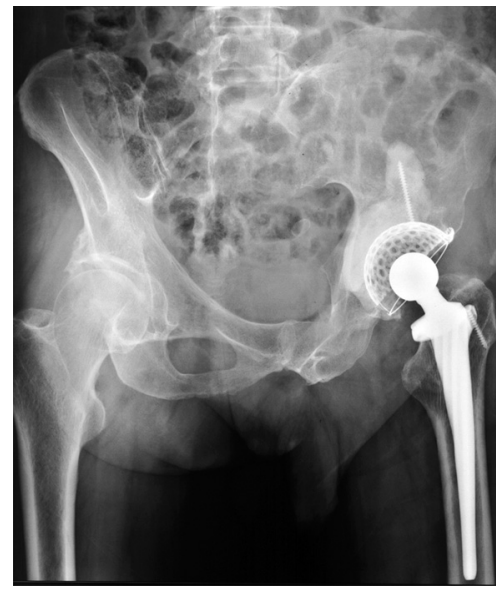

Fig. 1b

Figure 1a - CT scan of a 60-year-old man with metastatic carcinoma of the bronchus, showing involvement of the medial wall and anterior column. Figure $1 \mathrm{~b}$ - anteroposterior radiograph taken nine months post-operatively showing the antiprotrusio titanium acetabular mesh placed over a deficient acetabulum with cement filling the supra-acetabular defect.

was calculated from the date of surgery to death, or to the date of the last follow-up. The indications for surgery were intractable pain unresponsive to conservative treatment, significant interference with mobility, a slow to moderately growing tumour, and a primary tumour that was stable after chemotherapy and/or radiotherapy.

Imaging of the symptomatic region with plain radiographs and cross-sectional studies (MRI or/and CT) was undertaken in all patients to assess the intra- and extraosseous extent of the tumour. A whole-body bone scan was also routinely performed. Complete evaluation of the ipsilateral femur was carried out so that synchronous metastases could be treated appropriately. Percutaneous coreneedle biopsy was performed on patients with an unknown primary tumour. Internal iliac vessel embolisation was performed in six patients on the day before their operation.

Ipsilateral internal iliac artery ligation and temporary occlusion of the abdominal aorta with nylon tape or an intra-aortic balloon catheter were used in selected cases of tumours with excessive blood supply, those tumours with a diameter of $>10 \mathrm{~cm}$, and those with involvement of the sacroiliac joint, in order to minimise intra-operative blood loss. ${ }^{13}$ Thus the internal iliac artery was ligated in 14 patients, eight of whom also had temporary occlusion of the abdominal aorta using a nylon tape. An intra-aortic balloon catheter was used in eight patients.

Resection of the tumour was carried out using different surgical approaches depending on the extent and location of the individual tumour. According to Harrington's classification, ${ }^{5}$ patients with a class I defect were treated by routine hip replacement and cement augmentation on the acetabular side through a lateral transgluteal approach. For other types of defect, a T-shaped incision consisting of some or all of an extended ilioinguinal incision combined with a Smith-Petersen approach was used. ${ }^{14}$ Gross tumour and bone fragments were removed until solid bone could be palpated. For class II defects, a type of antiprotrusio titanium acetabular mesh (Link, Hamburg, Germany), with a small peripheral lip which sits on the lateral cortex of the ilium above the acetabulum, was placed over the deficient medial wall to prevent extravasation of cement into the pelvis. Additional fixation screws were placed through the dome before cementing in a polyethylene cup, which varied according to the prostheses being employed (Fig. 1). An Endo-Model Partial Pelvis Replacement (Link, Hamburg, Germany) was used for class III defects treated by curettage. These devices include a groove for implantation of a cemented acetabular component, and two or three fixation arms for screw fixation to the surrounding pelvic rim (Fig. 2). After resection of the femur a conventional cemented femoral component was used. If the tumour involved the proximal femur, it was replaced by a femoral endoprosthesis. For class IV defects, a modular hemipelvic endoprosthesis (Chunli, Beijing, China) ${ }^{15}$ was used after en bloc resection of the tumour (Fig. 3). The femoral side was then reconstructed using a standard component.

Quality of life was assessed using the European Organisation for Research and Treatment of Cancer core qualityof-life questionnaire (EORTC QLQ-C30). ${ }^{16}$ This has nine multi-item scales: five functional scales (physical, role, emotional, social and cognitive function), three symptom scales (pain, fatigue and financial difficulties), and a global health and quality-of-life scale. Each health profile is scored on a 100-point scale: a higher score in the functional scale indicates less disability, whereas a higher score in the symptom scales reflects a heavier symptomatic burden. A higher score on the global health and quality-of-life scale indicates better health and better quality of life. The Eastern Cooperative Oncology Group (ECOG) performance status grades ${ }^{17}$ were also collected. This measures functional performance on a scale from 0 to 4 , where 0 represents normal activity and 4 signifies totally bedridden. Function related 


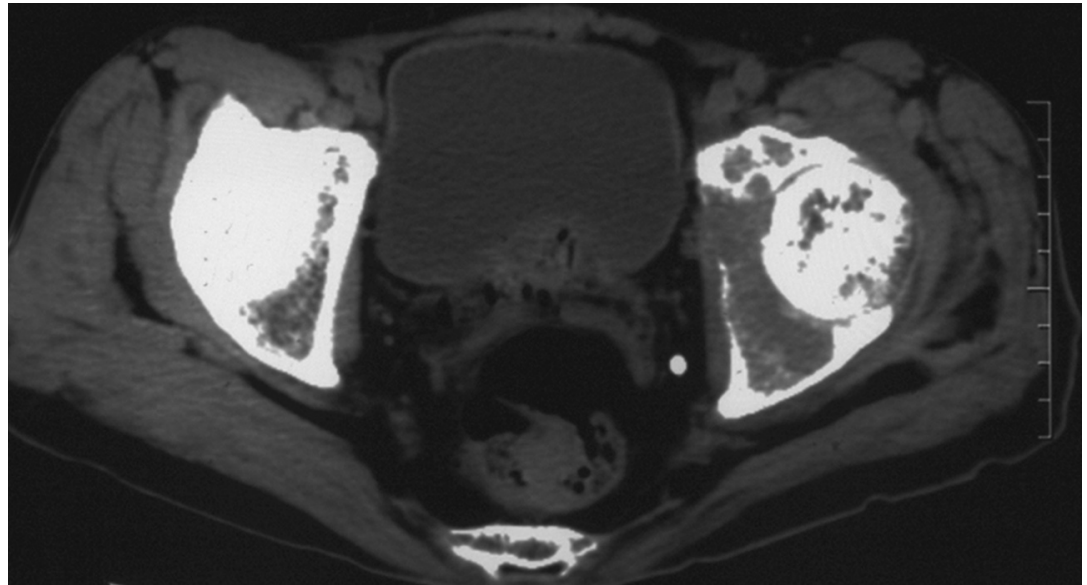

Fig. 2a

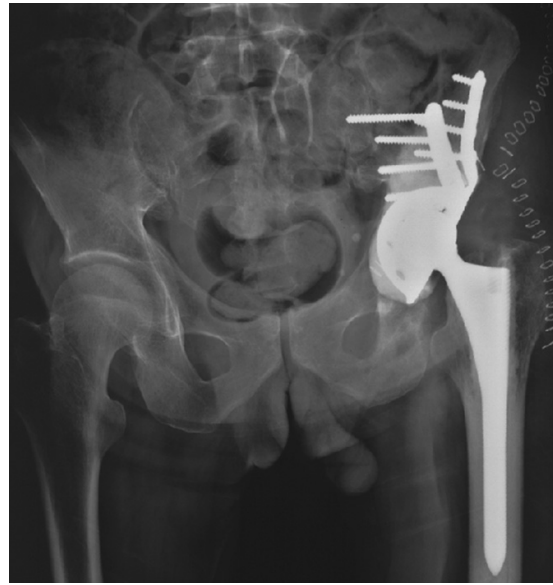

Fig. 2b

Figure 2a - CT scan of a 73-year-old man with carcinoma of the bronchus, showing a metastasis to the left acetabulum with completely destruction of the medial and lateral wall as well as the anterior and posterior columns. Figure $2 \mathrm{~b}-$ immediate post-operative radiograph showing the reconstruction using an Endo-Model partial pelvis replacement and a cemented total hip replacement. The patient could walk independently after surgery, but died ten months post-operatively from systemic spread of the primary tumour.

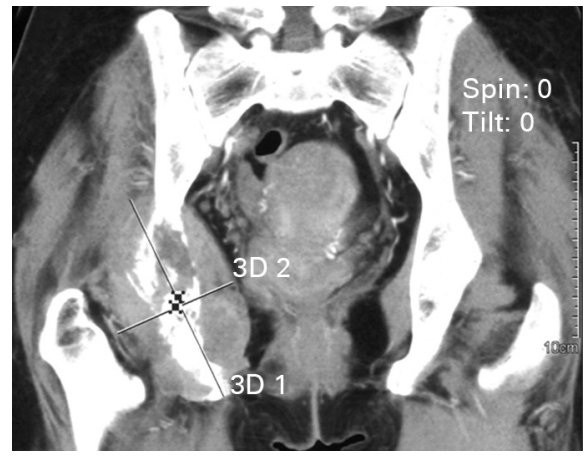

Fig. 3a

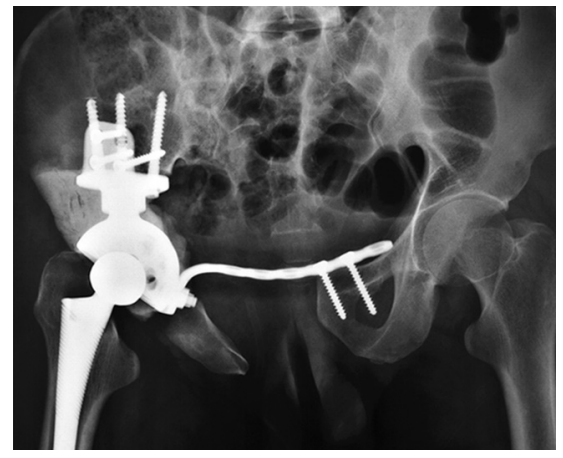

Fig. $3 b$

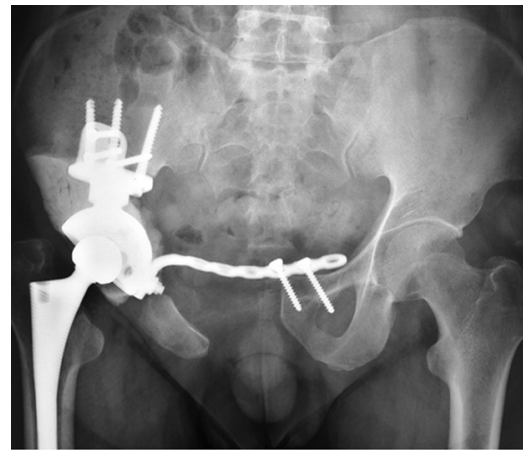

Fig. 3c

Figure 3a-CT scan of a 43-year-old woman with renal cell carcinoma and a right peri-acetabular metastasis found 4.5 years after the primary diagnosis, showing involvement of the acetabulum with an extensive soft tissue mass. Figures $3 b$ and $3 c-$ radiographs b) immediately post-operatively, showing the right hemipelvis reconstructed with a modular pelvic prosthesis, and c) at 13 months post-operatively, showing no local progression of the tumour.

to surgical treatment was assessed using the Musculoskeletal Tumor Society (MSTS 93) system developed by Enneking and Dunham. ${ }^{18}$

Statistical analysis. Statistical analysis was carried out using SPSS software package version 16.0 (SPSS Inc., Chicago, Illinois). The Kaplan-Meier approach was used to estimate survival probabilities and median survival times. The logrank test was used to compare the survival of subgroups. Paired $t$-tests were used to assess the significance of the difference between the pre-operative and most recent scores. A p-value $<0.05$ was chosen to represent significance. Because the QLQ-C30 was a multidimensional method of assessment, each domain was analysed and presented separately.

\section{Results}

There were 28 women and 18 men, with a mean age of at the time of surgery of 56.4 (20 to 73 ). The mean time from the diagnosis of the primary cancer to the manifestation of
Table I. Extent and distribution of the 46 primary cancers

\begin{tabular}{llll}
\hline & & \multicolumn{2}{l}{ Extent of disease } \\
\cline { 3 - 4 } Primary site & $\begin{array}{l}\text { Number of } \\
\text { patients }\end{array}$ & $\begin{array}{l}\text { Multiple skeletal Visceral } \\
\text { metastases }\end{array}$ & $\begin{array}{l}\text { organ } \\
\text { Total }\end{array}$ \\
Lung & 46 & 19 & 11 \\
Kidney & 11 & 5 & 1 \\
Breast & 10 & 4 & 4 \\
Multiple myelom & 7 & 2 & 3 \\
Liver & 4 & 2 & 0 \\
Prostate & 3 & 1 & 1 \\
Other sites & 3 & 2 & 0 \\
\hline
\end{tabular}

the acetabular lesion was 21.6 months ( 2 to 23 ). The mean follow-up was 19.2 months (4 to 70). A total of 19 patients $(41.3 \%)$ had multiple bone metastases and $11(23.9 \%)$ had visceral metastases. Table I summarises the extent of disease by site of the primary tumour, and the details of the surgery are summarised in Table II. 
Table II. Demographics and operative details of the 46 patients

\begin{tabular}{|c|c|c|c|}
\hline & $\begin{array}{l}\text { Number of } \\
\text { patients }\end{array}$ & $\begin{array}{l}\text { Local } \\
\text { recurrence }\end{array}$ & Complications \\
\hline \multicolumn{4}{|l|}{ Harrington classification ${ }^{5}$} \\
\hline 1 & 9 & 0 & 0 \\
\hline II & 16 & 3 & 1 \\
\hline III & 17 & 2 & 2 \\
\hline IV & 4 & 1 & 1 \\
\hline \multicolumn{4}{|l|}{ Extent of involvement } \\
\hline Peri-acetabular & 25 & 3 & 1 \\
\hline Ilium and peri-acetabular & 9 & 1 & 1 \\
\hline Peri-acetabular and obdurator pubic and ischium & 11 & 2 & 1 \\
\hline Whole hemipelvis & 1 & 0 & 1 \\
\hline \multicolumn{4}{|l|}{ Excision } \\
\hline En bloc & 14 & 1 & 2 \\
\hline Curettage & 32 & 5 & 2 \\
\hline \multicolumn{4}{|l|}{ Reconstruction* } \\
\hline THR & 5 & 0 & 0 \\
\hline $\mathrm{THR}+$ mesh & 17 & 3 & 1 \\
\hline THR + Endo-Model & 11 & 2 & 1 \\
\hline Partial pelvic replacement modular hemipelvis endoprosthesis & 12 & 1 & 2 \\
\hline
\end{tabular}

* one patient required amputation. THR, total hip replacement

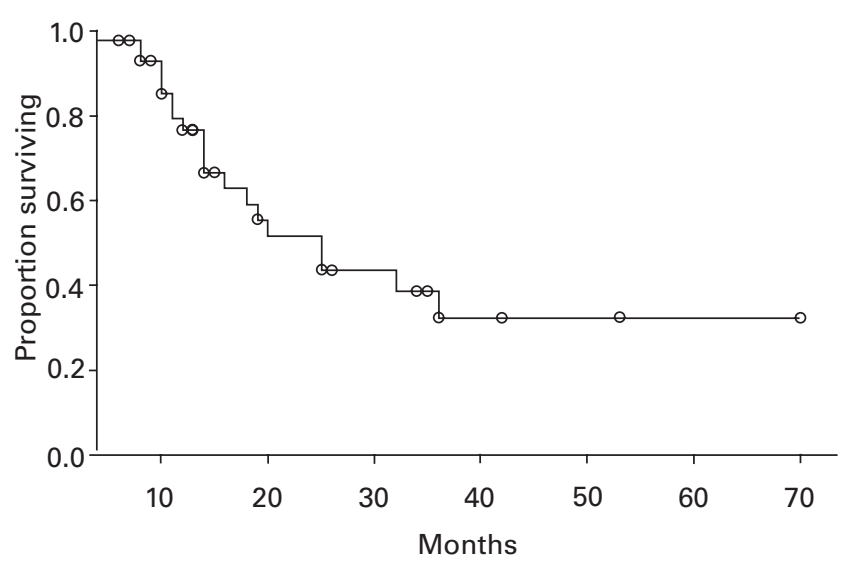

Fig. 4

Kaplan-Meier survival curve of 46 patients with peri-acetabular metastases.

Results of surgical treatment. The mean blood loss was $2464.1 \mathrm{ml} \mathrm{(300} \mathrm{to} 10500$ ) and the mean operative time was 3.6 hours ( 2 to 6 ). There were no peri-operative deaths. Adjuvant treatment was used in 37 (80.4\%) patients: systemic chemotherapy in 16 cases, radiotherapy in nine and combination therapy in 12 .

There were ten major post-operative complications in eight patients $(17.4 \%)$, including six cases of local progression of disease, two cases of deep infection and two cases of dislocation. Four of these eight patients received chemotherapy for their primary tumour. The mean time to local progression of disease was 7.5 months (3 to 12). Two deep infections were successfully treated with debridement. Six patients with local recurrence had a further tumour resection; one with renal cell carcinoma survived. Hip dislocations were treated by revision.

A total of 26 patients $(56.5 \%)$ were alive at follow-up and 20 patients died of primary tumour progression at between 4 and 36 months after the peri-acetabular operation. The Kaplan-Meier curve for overall survival is shown in Figure 4. The median survival of the 46 patients was 25 months; of the survivors at final follow-up, 17 were with disease and nine were disease-free. All those with myeloma and carcinoma of the prostate survived. The ten patients with renal cell carcinoma had a median survival of 36.0 months (interquartile range (IQR) 25 to $\mathrm{n} / \mathrm{a}$ ), patients with breast carcinoma 16.0 months (IQR 16 to n/a), lung cancer 14.0 months (IQR 10 to 19), and hepatic carcinoma 11.0 months (IQR 10 to $\mathrm{n} / \mathrm{a}$ ). The cause of death in each case was progression of the disease. The mean period of survival of patients with visceral metastases was 17.0 months (95\% CI 10.4 to 23.6 ), whereas that of patients without visceral metastases was 42.1 months (95\% CI 30.7 to 53.4) ( $\mathrm{p}=0.01)$. Patients with multiple skeletal metastases had a shorter mean survival (29.8 months, $95 \%$ CI 18.2 to 41.5 ) than patients with a solitary metastasis (32.6 months, 95\% CI 22.7 to 42.5 ), although no significant difference was found $(\mathrm{p}=0.50)$.

Post-operative function. The mean MSTS 93 score was $56.3 \%(6.7 \%$ to $90.0 \%)$ for all 46 patients at latest followup. Of each patient's last follow-up, a total of ten of the 46 patients needed medication for constant pain, one of whom had severe pain requiring the continuous use of narcotics. Nine had moderate pain requiring the periodic use 
Table III. Pre-operative and latest post-operative Eastern Cooperative Oncology Group (ECOG) performance status grades ${ }^{17}(n, \%)$

\begin{tabular}{|c|c|c|c|c|c|c|c|}
\hline & & \multicolumn{6}{|c|}{ Latest post-operative grade } \\
\hline & & 0 & 1 & 2 & 3 & 4 & Total \\
\hline \multirow{6}{*}{$\begin{array}{l}\text { Pre-operative } \\
\text { grade }\end{array}$} & 0 & & & & & & \\
\hline & 1 & & $2(4.3)$ & $1(2.2)$ & & & $3(6.5)$ \\
\hline & 2 & $1(2.2)$ & $4(8.7)$ & $5(10.9)$ & $3(6.5)$ & $1(2.2)$ & $14(30.4)$ \\
\hline & 3 & & $10(21.7)$ & $6(13.0)$ & $2(4.3)$ & & $18(39.1)$ \\
\hline & 4 & & & $6(13.0)$ & $5(10.9)$ & & $11(23.9)$ \\
\hline & Total & $1(2.2)$ & $16(34.8)$ & $18(39.1)$ & $10(21.7)$ & $1(2.2)$ & $46(100.0)$ \\
\hline
\end{tabular}

Table IV. Quality of life before and after surgical treatment (mean, SD)

\begin{tabular}{lccc}
\hline & $\begin{array}{l}\text { Pre-operative } \\
\text { scores }\end{array}$ & $\begin{array}{l}\text { Latest post- } \\
\text { operative scores }\end{array}$ & p-value \\
\hline Global quality of life & $42.8(13.7)$ & $58.0(12.5)$ & 0.001 \\
Functional scales & & & \\
$\quad$ Physical & $50.3(21.2)$ & $59.1(17.4)$ & 0.102 \\
$\quad$ Role & $54.5(19.4)$ & $55.3(18.1)$ & 0.862 \\
Emotional & $66.3(18.5)$ & $70.5(18.9)$ & 0.118 \\
Cognitive & $80.3(16.8)$ & $82.6(14.1)$ & 0.329 \\
$\quad$ Social & $43.2(21.0)$ & $45.5(21.3)$ & 0.480 \\
Symptom scales & & & \\
$\quad$ Fatigue & $34.3(17.1)$ & $30.3(13.8)$ & 0.247 \\
$\quad$ Nausea and vomiting & $3.0(8.4)$ & $1.5(4.9)$ & 0.247 \\
$\quad$ Pain & $59.1(18.3)$ & $29.5(19.9)$ & 0.000 \\
$\quad$ Dyspnoea & $19.7(24.5)$ & $13.6(16.8)$ & 0.162 \\
$\quad$ Sleep & $31.8(24.1)$ & $33.3(23.0)$ & 0.771 \\
$\quad$ Appetite loss & $16.7(20.0)$ & $15.2(19.9)$ & 0.715 \\
$\quad$ Constipation & $18.2(19.9)$ & $15.2(19.9)$ & 0.329 \\
$\quad$ Diarrhoea & $4.5(11.7)$ & $5.8(14.6)$ & 1.000 \\
$\quad$ Financial difficulties & $50.0(39.5)$ & $59.1(39.8)$ & 0.056 \\
\hline
\end{tabular}

of narcotics, and five had mild pain requiring the use of non-narcotic analgesics. The mean rating out of 5 for emotional acceptance was 2.5 (0 to 5). In all, 25 patients (54\%) required at least the occasional use of a stick or one crutch at their last follow-up, and 21 patients could walk without support. The mean score for support was 2.8 out of 5 . The mean score out of 5 for walking was 3.1 (0 to 5). A total of 25 patients were able to walk outdoors; 12 had a limited ability to walk outdoors, and nine could walk only indoors. All but one patient had an altered gait. The mean score out of 5 for gait was 2.8 (0 to 5 ).

Improvements of performance status and QoL. The mean preand post-operative ECOG grades for all 46 patients were 2.8 (SD 0.98) and 1.9 (SD 0.86), respectively. Post-operatively, 17 patients $(37.0 \%$ ) performed well (an ECOG status of 0 or 1) compared with three $(6.5 \%)$ pre-operatively. The pairedsamples $t$-test showed a statistically significant improvement in ECOG status $(\mathrm{p}<0.001)$. Improvement in performance was seen in 32 of the 46 patients $(69.6 \%)$. The performance of nine patients remained unchanged and five $(10.9 \%)$ deteriorated (Table III).

The mean functional and symptom scores of QLQ-C30 before surgery and at a mean follow-up of 19.2 months are shown in Table IV. Only the 26 surviving patients could be included in this analysis. Paired-samples $t$-test examination of the post-operative scores at three months (58.0 (SD 12.5)) showed a significant improvement in QoL from the preoperative scores $(42.8$ (SD 13.7)) $(\mathrm{p}=0.001)$. No substantial emotional deficiency was found in this group. Also, no statistical difference was found in other functional scales between the pre- and post-operative scores. Significant improvement was seen in the symptom domains of pain and pain-related restrictions in daily activities. In all, 20 (77.3\%) out of the 26 surviving patients were found to have been relieved of pain at a mean follow-up of 19.2 months.

\section{Discussion}

The treatment of metastatic disease of the acetabulum is a fine balance between survival, function and overall QoL. Because of the patient's limited life expectancy, function and QoL are profoundly important considerations. ${ }^{8,12,19}$ If their symptoms can be controlled and a satisfactory level of function achieved, they may be able to return home and have some social life. Understanding how they function after surgery is the first step in optimising their treatment. ${ }^{11,20}$ An understanding of the relationship between pain, function and QoL will help the surgeon decide when to consider reconstructive surgery.

There is no doubt that in appropriately selected patients, surgical treatment can improve various aspects of quality of life, such as pain and mobility. However, the effect of this surgery on their overall quality of life has not previously been discussed. Published studies using validated outcomes tools to assess QoL after surgical treatment of bony metastases are rare. ${ }^{8}$ Furthermore, surgery for pelvic metastases is associated with significant morbidity, which may adversely affect other aspects of quality of life. Currently, there are no specific guidelines as to when to intervene surgically. This depends on the patient's wishes, the surgeon's experience, the perceived efficacy of medication and radiation, and nutritional and haematological parameters, and is necessarily tailored to the individual. ${ }^{11}$ Our results have shown that surgical intervention reduces pain and improves the overall QoL in patients with acetabular metastases who undergo reconstructive surgery.

Marco et $\mathrm{al}^{6}$ reviewed 55 patients who underwent pelvic reconstruction and suggested modifying the Harrington system of evaluating metastatic disease of the acetabulum. 
The two-year survival in our series was $51.5 \%$ which is similar to the $52 \%$ reported by Harrington. ${ }^{5}$ Vena et $\mathrm{al}^{21}$ described the outcome of 21 patients with peri-acetabular metastases. Their mean post-operative survival was 14.5 months. The nature of the primary tumour and the degree of its systemic progression are important determinants of life expectancy. ${ }^{6}$ Althausen et al $^{22}$ reported that long-term disease-free intervals can be achieved in patients who have undergone resection of a primary tumour of the kidney with an isolated metastasis in bone. More than half the patients in our study had a primary tumour of slow to moderate growth, such as cancer of the breast, thyroid or kidney. Six of the nine patients who died within a year of surgery for peri-acetabular metastases had cancer of the lung or liver. Local recurrence occurred in six patients in our study. Three of the six cases were reconstructed with an antiprotrusio mesh, and two had partial replacement of the pelvis. The relatively lower local recurrence rate in this group of patients may be attributed to en bloc resection and more aggressive local and systemic treatment. Yasko et $\mathrm{al}^{23}$ reported no local recurrence after en bloc resection for periacetabular metastases in 14 consecutive patients. In our series, this was carried out in $14(30.4 \%)$ patients and aggressive adjuvant treatment was used in $37(80.4 \%)$. The four patients who had a recurrence were all treated by curettage, and three of these received no adjuvant treatment. The comparatively low complication rate was attributed to a highly trained, multi-surgeon team, operating expeditiously, and to effective intra-operative control of haemorrhage.

Harrington's classification ${ }^{5}$ is generally used to describe the extent of metastatic disease of the acetabulum. According to this classification, patients with a class I defect can be treated by routine hip replacement with cement augmentation of the acetabular and femoral side. A titanium mesh is often incorporated to support the medial wall and to prevent migration of the cement and acetabular component into the pelvis. A variety of antiprotrusio acetabular devices have been developed to reinforce the margins of the acetabulum, which may make reconstruction easier. No threaded pins, inserted either antegradely or retrogradely, were used for reinforcement in this study. For some type II defects, the Endo-Model partial pelvic replacement was used instead of threaded pins.

En bloc resection may be more appropriate when advanced disease precludes internal fixation, or when the metastatic disease is limited to a solitary bony deposit. Falkinstein, Ahlmann and Menedez ${ }^{24}$ reported 13 patients with peri-acetabular metastases who underwent en bloc resection and prosthetic reconstruction. Of the 14 patients in our series who underwent en bloc resection, 12 had a solitary bony metastasis. Six of these 14 patients had metastases from a renal cell carcinoma.

Reconstruction after en bloc resection inherently increases the complexity of surgery. Satisfactory results have been reported following the use of the modular hemipelvic endoprosthesis. ${ }^{15}$ In our series, most of the metastases were large, with extrapelvic soft-tissue extension. Eight of the patients had involvement of the ilium and/ or obturator pubic and ischium. In one patient with breast cancer the whole hemipelvis was involved. One $(8.3 \%)$ local recurrence was seen three months post-operatively. The complication rate for the 14 patients who underwent en bloc resection was $14.3 \%$, higher than that for those who had undergone curettage $(6.3 \%)$. No survival benefit was found from en bloc resection compared with curettage $(\mathrm{p}=0.61)$. En bloc spondylectomy for spinal metastases has been developed in recent years. ${ }^{25}$ The value of en bloc resection for peri-acetabular metastases remains undetermined.

The mean post operative MSTS 93 score was compared with others in the literature. Vena et $\mathrm{al}^{21}$ described the outcome of 21 patients with a mean MSTS 93 score of $47.3 \%$. Ho et $\mathrm{al}^{8}$ reported a mean post-operative MSTS 93 score of $67 \%$ in 37 patients with peri-acetabular metastases. However, the MSTS 93 scores in our cohort were lower than those following the treatment of primary malignancies of the peri-acetabular region. ${ }^{15,26}$ This may be because of the general condition of the patients, most of whom received chemo- and/or radiotherapy for primary cancer, and systemic progression of the metastatic disease. The physical activity level of the patients was improved significantly according to their ECOG scores. A total of 17 (37.0\%) patients performed well (an ECOG status of 0 or 1 ) postoperatively, compared with three $(6.5 \%)$ pre-operatively.

A number of instruments have been used to assess global quality of life in patients with cancer. Most of these have been designed either for the general population or for patients who are undergoing potentially curative treatment for cancer. ${ }^{27}$ It is important to note that palliative care patients differ from these groups. The QLQ-C30 is a validated instrument used for the study of health-related quality of life in cancer patients. ${ }^{20}$ The QLQ-C30 assessment showed a statistically significant improvement after surgery for overall health status. We found significant changes only for global QoL and pain. This confirms the central importance of pain in a patient's overall assessment of quality of life. Some studies have found a statistically significant correlation between QoL and survival time. ${ }^{28,29}$ It is reasonable to expect that an improvement in the control of pain would result in an improvement in QoL. As pain becomes more severe, it will have a greater effect on function. ${ }^{12}$ The post-operative QLQ-C30 scores were close to those results reported by Hoffmann et $\mathrm{al}^{26}$ after the treatment of patients with primary malignancy of the pelvis.

This study has limitations, the main one being an inability to analyse how function and QoL change with time. The best way to evaluate post-operative function is by dynamic analysis and follow-up at different intervals after surgery. Owing to well-recognised difficulties in clinical follow-up, insufficient data were collected for analysis. However, the overall influence of surgery on outcome at a certain time point was still helpful when considering surgical 
intervention. There was no control group, for which it is unlikely that ethical approval would have been granted. The instruments used have all been validated in previous studies, but their limitations also need to be noted. Only half the patients survived, so the complication rate may not be accurate. A longer period of follow-up may reveal a higher complication rate. Despite these limitations, this study clearly shows that, in patients who have metastatic involvement of the acetabulum, surgical intervention offers benefits in terms of pain relief and improved QoL, with an acceptable rate of complications.

No benefits in any form have been received or will be received from a commercial party related directly or indirectly to the subject of this article.

\section{References}

1. Janjan N. Bone metastases: approaches to management. Semin Oncol 2001;28(Suppl 11):28-34.

2. Jacofsky DJ, Papagelopoulos PJ, Sim FH. Advances and challenges in the surgical treatment of metastatic bone disease. Clin Orthop 2003;415(Suppl):14-18.

3. Papagelopoulos PJ, Mavrogenis AF, Soucacos PN. Evaluation and treatment of pelvic metastases. Injury 2007;38:509-20.

4. Damron TA, Sim FH. Surgical treatment for metastatic disease of the pelvis and the proximal end of the femur. Instr Course Lect 2000;49:461-70.

5. Harrington KD. The management of acetabular insufficiency secondary to metastatic malignant disease. J Bone Joint Surg [Am] 1981;63-A:653-64.

6. Marco RA, Sheth DS, Boland PJ, et al. Functional and oncological outcome of acetabular reconstruction for the treatment of metastatic disease. J Bone Joint Surg [Am] 2000;82-A:642-51.

7. Tillman RM, Myers GJ, Abudu AT, Carter SR, Grimer RJ. The three-pin modified 'Harrington' procedure for advanced metastatic destruction of the acetabulum. $J$ Bone Joint Surg [Br] 2008;90-B:84-7.

8. Ho L, AhImann ER, Menendez LR. Modified Harrington reconstruction for advanced periacetabular metastatic disease. J Surg Oncol 2010;101:170-4.

9. Allan DG, Bell RS, Davis Al, et al. Complex acetabular reconstruction for metastatic tumor. J Arthroplasty 1995;10:301-6.

10. Benevenia J, Cyran FP, Biermann JS, Patterson FR, Leeson MC. Treatment of advanced metastatic lesions of the acetabulum using the saddle prosthesis. Clin Orthop 2004;426:23-31.

11. Patterson FR, Peabody TD.Operative management of metastases to the pelvis and acetabulum. Orthop Clin North Am 2000;31:623-31.
12. Cheng EY. Prospective quality of life research in bony metastatic disease. Clin Orthop 2003;415(Suppl):289-97.

13. Tang $\mathbf{X}$, Guo W, Yang R, et al. Evaluation of blood loss during limb salvage surgery for pelvic tumours. Int Orthop 2009;33:751-6.

14. Lackman RD, Crawford EA, Hosalkar HS, King JJ, Ogilvie CM. Internal hemipelvectomy for pelvic sarcomas using a T-incision surgical approach. Clin Orthop 2009;467:2677-84.

15. Guo W, Li D, Tang $\mathbf{X}$, et al. Reconstruction with modular hemipelvic prostheses for periacetabular tumor. Clin Orthop 2007;461:180-8.

16. Aaronson NK, Ahmedzai S, Bergman B, et al. The European Organization for Research and Treatment of Cancer OLQ-C30: a quality-of-life instrument for use in international clinical trials in oncology. J Nat/ Cancer Inst 1993;85:365-76.

17. Oken MM, Creech RH, Tormey DC, et al. Toxicity and response criteria of the Eastern Cooperative Oncology Group. Am J Clin Oncol 1982;5:649-55.

18. Enneking WF, Dunham WK. Resection and reconstruction for primary neoplasms involving the innominate bone. J Bone Joint Surg [Am] 1978;60-A:731-46.

19. Wunder JS, Ferguson PC, Griffin AM, Pressman A, Bell RS. Acetabular metastases: planning for reconstruction and review of results. Clin Orthop 2003;415(Suppl):187-97.

20. Falicov A, Fisher CG, Sparkes J, et al. Impact of surgical intervention on quality of life in patients with spinal metastases. Spine 2006;31:2849-56.

21. Vena VE, Hsu J, Rosier RN, O'Keefe RJ. Pelvic reconstruction for severe periacetabular metastatic disease. Clin Orthop 1999;362:171-80.

22. Althausen P, Althausen A, Jennings LC, Mankin HJ. Prognostic factors and surgical treatment of osseous metastases secondary to renal cell carcinoma. Cancer 1997;80:1103-9.

23. Yasko AW, Rutledge J, Lewis V0, et al. Disease- and recurrence-free survival after surgical resection of solitary bone metastases of the pelvis. Clin Orthop 2007:459:128-32

24. Falkinstein Y, AhImann ER, Menendez LR. Reconstruction of type II pelvic resection with a new peri-acetabular reconstruction endoprosthesis. J Bone Joint Surg $[\mathrm{Br}]$ 2008;90-B:371-6.

25. Yao KC, Boriani S, Gokaslan ZL, Sundaresan N. En bloc spondylectomy for spinal metastases: a review of techniques. Neurosurg Focus 2003;15:E6.

26. Hoffmann C, Gosheger G, Gebert C, Jürgens H, Winkelmann W. Functional results and quality of life after treatment of pelvic sarcomas involving the acetabulum. J Bone Joint Surg [Am] 2006;88-A:575-82.

27. Cella DF. Quality of life outcomes: measurement and validation. Oncology 1996;10(Suppl):233-46.

28. Hoskin PJ, Grover A, Bhana R. Metastatic spinal cord compression: radiotherapy outcome and dose fractionation. Radiother Oncol 2003;68:175-80.

29. Zaidat 00, Ruff RL. Treatment of spinal epidural metastasis improves patient survival and functional state. Neurology 2002;58:1360-6. 